\title{
Patient-reported-outcomes in subjects with painful lumbar or cervical radiculopathy treated with pregabalin: evidence from medical practice in primary care settings
}

\author{
María Teresa Saldaña $\cdot$ Ana Navarro $\cdot$ \\ Concepción Pérez $\cdot$ Xavier Masramón · Javier Rejas
}

Received: 28 October 2008 / Accepted: 5 August 2009 / Published online: 2 October 2009

(C) The Author(s) 2009. This article is published with open access at Springerlink.com

\begin{abstract}
The objective of this study was to evaluate the effect of pregabalin in painful cervical or lumbosacral radiculopathy treated in Primary Care settings under routine clinical practice. An observational, prospective 12week secondary analysis was carried-out. Male and female above 18 years, naïve to PGB, with refractory chronic pain secondary to cervical/lumbosacral radiculopathy were enrolled. SF-MPQ, Sheehan Disability Inventory, MOS Sleep Scale, Hospital Anxiety and Depression Scale and the EQ-5D were administered. A total of 490 (34\%) patients were prescribed PGB-monotherapy, 702 (48\%) received PGB add-on, and 159 (11\%) were administered non-PGB drugs. After 12 weeks, significant improvements in pain, associated symptoms of anxiety, depression and sleep disturbances, general health; and level of disability were
\end{abstract}

\section{T. Saldaña ( $\square)$}

Centro de Salud de Raíces, Av. del Campón 67,

33400 Castrillón (Asturias), Spain

e-mail: zatosaldana@yahoo.es

\section{T. Saldaña}

Raíces Primary Care Center, Castrillón, Asturias, Spain

\section{A. Navarro}

Puerta del Ángel Primary Care Center, Madrid, Spain

C. Pérez

Pain Clinic, De la Princesa Hospital, Madrid, Spain

X. Masramón

Department of Statistics,

European Biometrics Institute, Barcelona, Spain

J. Rejas

Health Outcomes Research Department,

Medical Unit, Pfizer Spain, Alcobendas, Spain

e-mail: olga.freire@pfizer.com observed in the three groups, being significantly greater in PGB groups. In routine medical practice, monotherapy or add-on pregabalin is associated with substantial pain alleviation and associated symptoms improvements in painful cervical or lumbosacral radiculopathy.

Keywords Radiculopathy · Pregabalin · Primary health care $\cdot$ Epidemiologic studies $\cdot$ Outcomes research $\cdot$ Clinical practice

\section{Introduction}

Spinal pain is the most common form of chronic pain [1], with prevalences of back pain in the general population of $15-45 \%$ [2-4], and of $13-22 \%$ in the case of cervical pain [5-7]. A neuropathic mechanism is implied in the genesis of this type of pain in 10-19\% of all patients with back pain [8-10], resulting in impaired quality of life, and increased utilization of health care resources and economical cost [10-12]. As in other types of chronic pain, patients with back pain not only suffer important comorbidities in the form of other painful disorders [10-12], but frequently also present with prominent sleep disturbances [13], as well as anxiety and mood disorders [14, 15].

Despite the introduction of new treatments, the management of patients with neuropathic pain remains a challenge [16]. In clinical practice, patients with neuropathic pain including those with spinal pain, often receive suboptimal treatment. In this context, the most widely used pharmacological treatments in these patients are nonsteroidal antiinflammatory drugs [10-12], which are scantly effective in the management of pain with a neuropathic component such as the one found in radiculopathies [17]. Such suboptimal treatment of neuropathic pain contributes substantially 
to the patient disease burden [18-20]. Although a number of therapies are available for neuropathic pain, including antidepressants, tramadol, opioids, and different antiepileptic drugs, the results of a recent systematic review suggest that, in view of their balance between efficacy and tolerability, gabapentin and pregabalin (PGB) can be regarded as first line treatments for peripheral pain with a neuropathic component [16]. In addition, these antiepileptic drugs, together with antidepressants, offer the advantage of acting not only on pain but also on the associated symptoms of depression [16]. The presence of psychological disorders in these subjects may exacerbate pain intensity and disability. Therefore, treatment with anticonvulsive drugs or antidepressants could optimize treatment effectiveness and reduce the occurrence of adverse events [21].

Pregabalin (PGB) is a structural analog of gammaaminobutyric acid (GABA) that selectively binds the alpha $_{2}$-delta $\left(\alpha_{2}-\delta\right)$ subunit, of voltage-dependent calcium channels, and which possesses analgesic, anxiolytic, and antiepileptic properties [22]. In placebo controlled clinical trials, PGB has demonstrated efficacy in ameliorating pain relief and in improving the affective component of pain and sleep disturbances in patients with peripheral diabetic neuropathy [23-26], postherpetic neuralgia [27-29], and spinal cord injury, a model of central neuropathic pain [30]. However, there is no information on the effect of PGB in patients with cervical or lumbosacral radiculopathy under routine clinical practice ("real world" conditions), these patients representing up to two-thirds of all cases of neuropathic pain in same studies [10].

The present work was conducted to show evidence from the clinical practice of the effect of PGB upon different Patient-Reported-Outcomes (PROs), representative of the multidimensional nature of these disorders, in a large group of subjects with painful cervical or lumbosacral radiculopathy treated in the primary care setting under conditions of routine clinical practice.

\section{Methods}

Study design

This work presents the results of a secondary analysis of a multicentre, observational (naturalistic) and prospective 12week study, whose objective was to assess the cost of refractory painful radiculopathy of cervical or lumbosacral origin in Primary Care Settings under real life conditions: the LIRA study [31]. The study was carried out between September 2005 and April 2006, and involved the participation of 381 primary care physicians randomly selected by quotas according to regional population density in Spain. This was a non-interventional study, and the analgesic treatment administered to the patients was determined by the clinical judgment of the supervising physician. The physician could substitute previous treatment with some other drug, or add a new drug to the existing treatment. In accordance to the Spanish recommendations, the study was approved by the Ethics Committee of Hospital de la Princesa (Madrid), and it was conducted in agreement with the principles contained in the Declaration of Helsinki for studies in humans.

The objective of this secondary analysis was to compare the effect of two patterns of PGB treatment, add-on and monotherapy (PGB add-on and PGB monotherapy groups), when compared with a treatment pattern not including PGB (non-PGB group) on pain alleviation and associated symptoms involving depression, anxiety, sleep, disability and, quality of life.

\section{Study population}

The original study included patients of both genders aged 18 years or older. The subjects were refractory to previous analgesia and suffered chronic pain with a duration of over 6 months. Refractory was defined as no pain reduction after treatment with at least one course of an analgesic in monotherapy. The pain was secondary to cervical radiculopathy, defined as neck pain irradiating towards the arms, or to lumbosacral radiculopathy, defined as lumbar or sacral pain irradiating to the calves or feet and exhibiting a distribution consistent with involvement of nerve root L5 or S1, respectively. In addition, the patients were required to present a score of $\geq 4$ in the DN4 neuropathic pain diagnostic questionnaire (see below), have a sufficient cultural and educational level to complete health questionnaires written in Spanish, and give their informed consent. This secondary analysis only included those patients who met the aforementioned selection criteria, and who had not received treatment with PGB prior to the start of the study.

The study sample size was defined for the primary endpoint of the LIRA study, i.e., the determination of cost and its evolution after 12 weeks of follow-up, under conditions of routine clinical practice in the PCS. Therefore, no sample size predetermination was made for the secondary analysis presented in this work.

\section{Clinical evaluations and measurement instruments}

The patients were followed-up for 12 weeks, and were evaluated twice: at baseline and at end of study. At the baseline visit, the clinicians administered the DN4 neuropathic pain diagnostic questionnaire, the selection criteria were checked, and patient sociodemographic data were collected, along with information on the duration of the disease and its treatment, and the use of health care and 
non-health care resource utilization in the 12 weeks prior to patient inclusion, as reflected in the patient case history. On both the baseline visit and after the 12 weeks of follow-up, the patients were required to complete the Short-Form McGill Pain Questionnaire (SF-MPQ), the Sheehan Disability Inventory (SDI), the Medical Outcomes Study Sleep Scale (MOS), the Hospital Anxiety and Depression Scale (HADS), and the EQ-5D. In addition, the patients kept a diary, with weekly recordings of pain intensity [visual ana$\log$ scale (VAS) of the SF-MPQ] and health status (health status VAS of the EQ-5D).

The DN4 (Douleur Neuropathique 4 questions) neuropathic pain diagnostic questionnaire consists of 10 items that describe different pain characteristics, and allows discrimination of neuropathic pain from non-neuropathic pain. If the patient exhibits a score of at least 4 out of 10 possible points (range $0-10$ ), the patient is considered to have neuropathic pain, with a sensitivity of $83 \%$ and a specificity of $90 \%$ [32-34].

The main component of the Short-Form McGill Pain Questionnaire (SF-MPQ) comprises 15 descriptors (11 sensory and 4 affective descriptors) that are scored on a scale of $0=$ no pain to $3=$ severe pain [35]. The sum of the different intensities in turn yields three pain scores: sensory, affective, and total. The second part of the SF-MPQ consists of a 100-mm VAS for scoring the intensity of the pain experienced by the patient in the previous week. The third part of the instrument is a measure of the intensity of pain at the time of the evaluation, and involves a 6-point scale from $0=$ no pain to $5=$ unbearable pain

The Sheehan Disability Inventory (SDI) is a simple and frequently used instrument that evaluates patient functional alteration in three domains: work, social life/leisure, and family life/home responsibilities [36]. Each domain is scored on an 11-point scale from $0=$ no impairment to $10=$ extremely impaired. The instrument contains two additional items that explore perceived stress and social support. The former is likewise scored on an 11-point scale, while perceived social support is scored on an 11-point scale expressed as percentages from $0 \%=$ no support to $100 \%=$ ideal support. The SDI yields three scores: the disability score consisting of the sum of the scores of the first three items, ranging from 0 to 30 ; the fourth item (perceived stress) score, ranging from 0 to 10; and the fifth item (social support) score, which, unlike the previous four scores, must be inverted.

The Medical Outcomes Study Sleep Scale (MOS) is a self-administered questionnaire that explores key aspects of sleep [37]. It consists of 12 items distributed into 6 subscales or domains: sleep disturbance, snoring, waking up with shortness of breath or headache, the adequacy of sleep, daytime somnolence, and amount of sleep. In addition, the MOS-sleep provides a summarizing index of sleep problems based on the scores of 9 of its items-the higher the score is, the worse the sleep, except when referring to the dimensions amount of sleep and adequacy of sleep, which are interpreted in the opposite manner. The scale has shown good psychometric properties in patients with neuropathic pain [38].

The Hospital Anxiety and Depression Scale (HADS) is also a self-administered instrument composed of 14 items, of which 7 explore symptoms of depression and 7 assess anxiety [39]. Each item is scored from 0 to 3 , where $0=$ no symptom and $3=$ most severe or frequent symptom. The two scores are obtained by adding the 7 items of each subscale - one relating to depression and the other to anxiety (HADS-D and HADS-A) - each score ranging from 0 to 21 points.

The EQ-5D questionnaire evaluates patient-perceived health [40]. It offers a generic measure of health based on 5 items that explore the degree of alteration in 5 dimensions: mobility, personal care, daily life activities, pain/discomfort, and anxiety/depression. The scores of the 5 items can be used to calculate a utility index that varies from -0.6 to 1.0 , where the highest scores correspond to better patient health. The instrument also includes a $20-\mathrm{cm}$ visual analog scale (EQ-5D VAS) ranging from $0=$ worst imaginable health status to $100=$ best imaginable health status.

As the original study was designed as an observational epidemiological research, forced adverse events reporting (i.e.: type of adverse event, seriousness, etc.) could not be implemented except to document the reason for discontinuation before the end of study visit.

\section{Statistical analysis}

For the statistical analysis of this secondary evaluation, and according to the treatment prescribed from the baseline visit as established by clinical judgment, the patients were divided into three groups: patients that substituted or added another drug other than PGB to previous treatment (NonPGB group); patients that substituted previous treatment with PGB as monotherapy (PGB monotherapy group); and patients that received PGB added onto the existing therapeutic regimen (PGB add-on group).

The baseline characteristics of the patients are reported as the mean and standard deviation for quantitative variables, while qualitative variables are represented as absolute and relative frequencies. Normality distribution assumptions were verified using the Kolmogorov-Smirnov test. Analysis of variance (ANOVA), the Kruskal-Wallis test, and the chi-square test were used to assess the baseline homogeneity of the variables in the three study groups.

The proportion of patients with a reduction of at least $50 \%$ in pain intensity as rated by the SF-MPQ pain VAS was calculated and defined as responders. The cumulative 
number of days without pain or with mild pain was calculated ( $<40 \mathrm{~mm}$ on the VAS of the SF-MPQ). In addition, the changes in the above mentioned scales and subscales versus baseline were used as assessment variables. The comparison between groups of the changes in quantitative variables versus baseline was carried out by analysis of covariance (ANCOVA), adjusting for the baseline score on each corresponding scale and the number of previous drugs. In turn, the changes in ordinal qualitative variables versus baseline were evaluated by means of a logistic regression model, adjusting for the baseline score and the number of previous drugs. These analyses were made in application to the included patients that completed the 12 weeks of follow-up, and for whom changes in the baseline variables could be calculated. The statistical significance of the comparisons between treatments groups was adjusted by means of the Tukey multiple comparisons method. All statistical tests were two-sided, and statistical significance was considered for $P<0.05$.

With the purpose of evaluating the clinical significance of the changes in the different measurements, a calculation was made of the effect size obtained, based on the difference between the means of a given measurement before and after treatment, divided by the corresponding standard deviation measured before treatment [41]. Interpretation of the effect size was based on the established criterion which considers an effect size of 0.20 to $<0.50$ as small; a size of $\geq 0.50$ and $<0.80$ as moderate; and a size of $\geq 0.80$ as large [41].

Based on the weekly patient scores corresponding to the VAS of the EQ-5D, calculations were made of the gains in QALYs (quality-adjusted life years) after 12 weeks of follow-up. The direct VAS score divided by 100 was used as an estimator of utility value (in metric terms $0-1$, where $0=$ death and $1=$ perfect health), from which the gain in QALYs was calculated. Trapezoidal approximation was used for this calculation, employing the baseline and weekly utility values as reference values [42].

\section{Results}

\section{Patient distribution}

A total of 1,879 patients were included in the LIRA study, of which 1,351 had not been previously exposed to PGB and met the inclusion/exclusion criteria for this secondary analysis. The analysis was finally performed in 1,304 patients $(96.5 \%)$ that completed the 12 weeks of the study. Figure 1 reports these data, along with the causes of patient losses to follow-up. Radiculopathy was of lumbar origin in $86.9 \%$ of cases, and of cervical origin in $13.1 \%$ (without

Fig. 1 Patient disposition

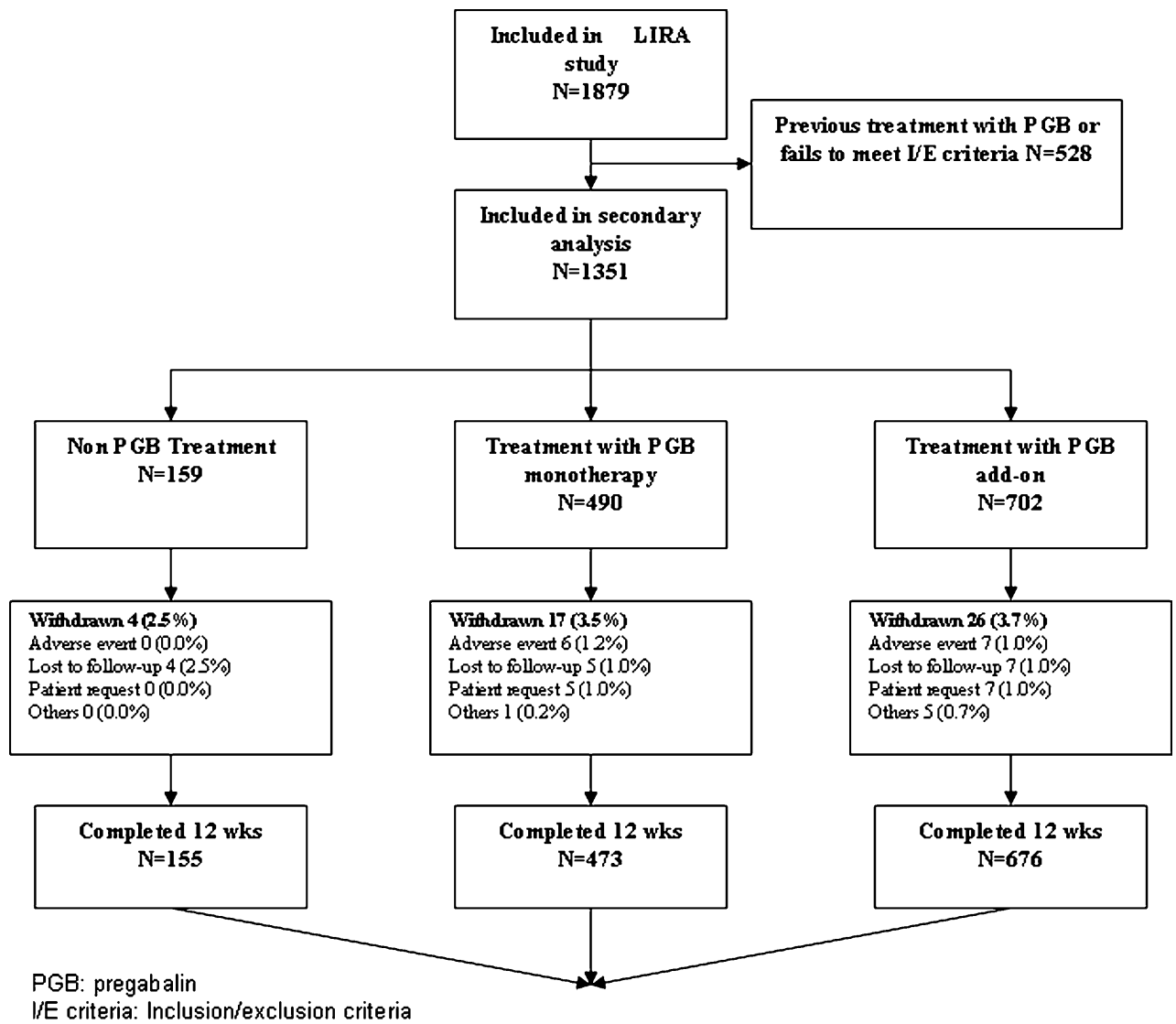


significant differences in this distribution according to treatment group).

Baseline demographic and clinical characteristics

The recruited population was of middle age, with a female predominance, and over half of the subjects were without working activity (Table 1). On average, patients had painful radiculopathy for 2 years and were treated with at least one curse of an analgesic. The most frequent previous treatments were analgesics, particularly nonsteroidal antiinflammatory drugs (NSAIDs), and paracetamol, which were used by at least $60 \%$ and almost $50 \%$ of the subjects, respectively. Frequency of previous drug use was numerically different between groups. However, except for vitamin use (more frequently used by PGB add-on group, $P<0.001$ ), differences in the others type of drug were hardly statistically significant (Table 1). The three treatment groups were similar in terms of demographics characteristics, with the exception of fewer previous treatments in the PGB monotherapy group versus the other two groups (Table 1). The patients in the PGB add-on group generally presented with poorer clinical conditions, with increased pain intensity, worst social and working activity, and poorer quality of life
(Table 2). Although of questionable clinical relevance, anxiety levels were significantly greater in the PGB add-on group than in the other two groups (Table 2). There were no differences with regard to sleep disturbances.

Drug therapy during study

Most of the patients in the non-PGB group (67\%) received two or more drugs for pain treatment [mean (SD): 2.2 (1.4)], the most frequent being paracetamol $(37 \%$, mean dose \pm standard deviation: $2.144 \pm 1.010 \mathrm{mg} /$ day), metamizol $(21 \%, 1,087 \pm 455)$, tramadol $(19 \%, 157 \pm 60 \mathrm{mg} /$ day $)$, ibuprofen $(17 \%, 1.094 \pm 451 \mathrm{mg} /$ day $)$, diclofenac $(16 \%, 88 \pm$ 49), gabapentin $(13 \%, 989 \pm 594 \mathrm{mg} /$ day $)$, tetrazepam $(8 \%$, $65 \pm 24 \mathrm{mg} /$ day $)$, diazepam ( $6 \%, 6 \pm 3 \mathrm{mg} /$ day $)$, fentanil $(6 \%, 59 \pm 23 \mathrm{mg} /$ day $)$, codeine $(6 \%, 59 \pm 23 \mathrm{mg} /$ day $)$, and amitriptyline $(5 \%, 38 \pm 28 \mathrm{mg} /$ day $)$. In the PGB monotherapy group, the mean dose was $187 \pm 106 \mathrm{mg} /$ day. The most frequently used drugs in the PGB add-on group (mean dose: $191 \pm 107 \mathrm{mg} /$ day) were paracetamol (42\%, $2.146 \pm$ $1.077 \mathrm{mg} / \mathrm{day})$, ibuprofen (21\%, $1.218 \pm 555 \mathrm{mg} / \mathrm{day})$, tramadol (20\%, $163 \pm 81 \mathrm{mg} /$ day), diclofenac (13\%, $126 \pm 52)$, metamizol $(11 \%, 1.517 \pm 863 \mathrm{mg} /$ day $)$, tetrazepam $(7 \%$, $80 \pm 42 \mathrm{mg} /$ day), diazepam (6\%, mean dose $7 \pm 4 \mathrm{mg} /$ day $)$,
Table 1 Demographic and clinical characteristics

NSAID Nonsteroidal antiinflammatory drug, $S D$ standard deviation, $A E D$ antiepileptic drug, $N P P$ neuropathic pain, $P G B$ pregabalin;

a Total number of patients analyzed; some subjects failed to report the data relating to certain variables

b The patients could have received more than one previous treatment

c Includes lidocaine, corticoids

\begin{tabular}{|c|c|c|c|c|}
\hline Characteristics & $\begin{array}{l}\text { Non-PGB } \\
(N=155)^{\mathrm{a}}\end{array}$ & $\begin{array}{l}\text { PGB } \\
\text { monotherapy } \\
(N=473)^{\mathrm{a}}\end{array}$ & $\begin{array}{l}\text { PGB } \\
\text { add-on } \\
(N=676)^{\mathrm{a}}\end{array}$ & $P$ \\
\hline Sex (female), $n(\%)$ & $90(57.8)$ & $262(55.3)$ & $377(55.8)$ & 0.879 \\
\hline Age (years), mean (SD) & $56.3(13.2)$ & $56.0(12.7)$ & $57.2(12.1)$ & 0.230 \\
\hline Body mass index $\left(\mathrm{kg} / \mathrm{m}^{2}\right)$ & $27.9(4.2)$ & $27.3(3.8)$ & $27.5(3.8)$ & 0.204 \\
\hline Marital status (married or with couple), $n(\%)$ & $120(77.2 \%)$ & $342(72.3 \%)$ & $498(73.6 \%)$ & 0.525 \\
\hline Labor status, $n(\%)$ & & & & 0.149 \\
\hline Active & $43(27.9)$ & $111(23.3)$ & $178(26.3)$ & \\
\hline Housewife & $26(16.9)$ & $70(14.7)$ & $114(16.8)$ & \\
\hline Sick leave & $21(13.6)$ & $44(9.1)$ & $98(14.5)$ & \\
\hline Unemployed & $9(5.8)$ & $18(3.7)$ & $26(3.7)$ & \\
\hline Retired & $46(29.9)$ & $199(42.1)$ & $231(34.1)$ & \\
\hline Unknown & $9(5.8)$ & $33(7.0)$ & $30(4.5)$ & \\
\hline Duration (years), mean (SD) & $2.1(3.7)$ & $2.1(4.1)$ & $1.9(3.4)$ & 0.117 \\
\hline No. previous treatments, mean (SD) & $2.8(1.7)$ & $2.2(1.3)$ & $2.7(1.4)$ & $<0.001$ \\
\hline \multicolumn{5}{|l|}{ Previous treatments ${ }^{\mathrm{b}}, n(\%)$} \\
\hline NSAID & $104(67.1)$ & $294(62.2)$ & $460(68.1)$ & 0.039 \\
\hline Paracetamol & $75(48.4)$ & $207(43.7)$ & $317(46.9)$ & 0.442 \\
\hline Metamizol & $41(26.4)$ & $96(20.2)$ & $134(19.8)$ & 0.174 \\
\hline Opioids & $63(40.6)$ & $136(28.8)$ & $219(32.4)$ & 0.022 \\
\hline Antiepileptic drug & $16(10.1)$ & $48(10.2)$ & $49(7.3)$ & 0.173 \\
\hline Tricyclic antidepressants & $14(8.8)$ & $24(5.1)$ & $59(8.8)$ & 0.049 \\
\hline Benzodiazepines & $21(13.5)$ & $78(16.5)$ & $137(20.2)$ & 0.077 \\
\hline Vitamins (B6,B12) & $17(11.0)$ & $25(5.3)$ & $88(13.1)$ & $<0.001$ \\
\hline Others $^{\mathrm{c}}$ & $10(6.4)$ & $19(4.0)$ & $78(11.5)$ & $<0.001$ \\
\hline
\end{tabular}


Table 2 Baseline visit patientreported health outcomes

$S D$ Standard deviation, VAS

visual analog scale, HADS

Hospital Anxiety Depression

Scale, MOS Medical Outcomes

Study, $P G B$ pregabalin,

$P P I$ present pain intensity,

$S D I$ Sheehan Disability

Inventory, $S F-M P Q$ Short Form

McGill Pain Questionnaire

${ }^{\text {a }}$ Total number of patients analyzed; some subjects failed to report the data relating to certain variables

b Sum of the scores of the three disability items

${ }^{c}$ Patients responding without problems in the item

\begin{tabular}{lllll}
\hline Health outcome & $\begin{array}{l}\text { Non-PGB } \\
(N=155)^{\mathrm{a}}\end{array}$ & $\begin{array}{l}\text { PGB } \\
\text { monotherapy } \\
(N=473)^{\mathrm{a}}\end{array}$ & $\begin{array}{l}\text { PGB } \\
\text { add-on } \\
(N=676)^{\mathrm{a}}\end{array}$ & $P$ \\
\hline
\end{tabular}

SF-MPQ, mean (SD)

\begin{tabular}{|c|c|c|c|c|}
\hline Sensory & $15.5(5.8)$ & $15.1(6.0)$ & $16.0(6.0)$ & 0.045 \\
\hline Affective & $4.8(3.3)$ & $4.4(3.2)$ & $5.0(3.2)$ & 0.012 \\
\hline Total & $20.3(8.4)$ & $19.5(8.4)$ & $21.0(8.5)$ & 0.016 \\
\hline PPI (0-5) & $2.7(0.8)$ & $2.7(0.8)$ & $2.8(0.8)$ & 0.014 \\
\hline VAS (0-100) & $71.4(15.3)$ & $70.4(14.6)$ & $72.7(15.3)$ & 0.032 \\
\hline \multicolumn{5}{|l|}{ MOS-sleep, mean (SD) } \\
\hline Summary index (0-100) & $47.6(16.9)$ & $46.2(17.2)$ & $48.4(17.2)$ & 0.096 \\
\hline Sleep disturbance $(0-100)$ & $50.6(20.1)$ & $48.5(19.5)$ & $51.96(19.6)$ & 0.015 \\
\hline Snoring (0-100) & $39.3(30.6)$ & $37.3(28.6)$ & $37.4(28.6)$ & 0.754 \\
\hline Shortness of breath $(0-100)$ & $30.1(25.4)$ & $29.5(26.6)$ & $31.3(26.0)$ & 0.539 \\
\hline Sleep quantity, hours & $5.8(1.5)$ & $5.8(1.4)$ & $5.6(1.3)$ & 0.004 \\
\hline Adequacy of sleep (100-0) & $39.1(23.6)$ & $40.0(23.1)$ & $36.8(23.2)$ & 0.067 \\
\hline Daytime somnolence (0-100) & $40.2(19.4)$ & $38.1(19.0)$ & $37.5(19.0)$ & 0.230 \\
\hline \multicolumn{5}{|l|}{ HADS, mean (SD) } \\
\hline Depression (0-21) & $10.8(4.5)$ & $10.0(4.5)$ & $10.7(4.4)$ & 0.014 \\
\hline Anxiety $(0-21)$ & $10.5(3.9)$ & $9.9(3.9)$ & $10.6(3.8)$ & 0.022 \\
\hline \multicolumn{5}{|l|}{ SDI, mean (SD) } \\
\hline Disability $(0-30)^{\mathrm{b}}$ & $18.9(6.0)$ & $18.4(5.8)$ & $20.0(5.4)$ & $<0.001$ \\
\hline Perceived stress $(0-100)$ & $6.0(2.1)$ & $5.9(2.1)$ & $6.3(1.9)$ & 0.007 \\
\hline Perceived social support, \% (0-100) & $58.1(22.3)$ & $56.0(22.4)$ & $57.4(23.6)$ & 0.503 \\
\hline \multicolumn{5}{|l|}{ EQ-5D } \\
\hline VAS, mean (SD) (0-100) & $42.3(17.2)$ & $42.5(18.2)$ & $38.9(17.5)$ & 0.002 \\
\hline Mobility $^{\mathrm{c}}, n(\%)$ & $53(34.9)$ & $134(28.9)$ & $181(27.0)$ & 0.051 \\
\hline Personal care $^{\mathrm{c}}, n(\%)$ & $59(38.8)$ & $203(43.8)$ & $264(39.5)$ & 0.156 \\
\hline Daily life activities ${ }^{\mathrm{c}}, n(\%)$ & $21(13.8)$ & $51(11.1)$ & $47(7.0)$ & $<0.001$ \\
\hline Without pain, $n(\%)$ & $5(3.3)$ & $11(2.4)$ & $8(1.2)$ & 0.002 \\
\hline Without anxiety/depression, $n(\%)$ & $37(24.5)$ & $127(27.4)$ & $150(22.5)$ & 0.010 \\
\hline
\end{tabular}

amitriptyline (5\%, $28 \pm 20 \mathrm{mg} /$ day), and fentanil (3\%, mean dose $48 \pm 23 \mathrm{mg}$ /day). The mean number of drugs during the study in this group was 2.8 (1.1).

Patient-Reported-Outcomes (PROs)

\section{Pain reduction}

The three groups showed significant and clinically relevant reductions in pain severity after 12 weeks of follow-up (Table 3). Pain reduction proved significantly greater in the groups administered PGB, with changes of 56 and $51 \%$, respectively, for PGB as monotherapy and add-on treatment, versus $36 \%$ in the patients who did not receive PGB $(P<0.0001$, Table 3$)$. The differences in pain reduction were significant from the fourth week, and maintained until the end of the study (Fig. 2) - resulting in an increased cumulative number of days with no/mild pain $(<40 \mathrm{~mm}$ on the VAS of the SF-MPQ) in the groups administered PGB versus the patients without PGB $(P<0.0001$, Table 3$)$. At the end of the study, 63 and $56 \%$ of the patients administered PGB as monotherapy and on an add-on basis, respectively, showed a $50 \%$ reduction in pain intensity (responders), versus $33 \%$ in the non-PGB group $(P<0.0001$, Table 3$)$.

\section{Other Patient-Reported-Outcomes measurements}

Improvements in comorbid conditions including sleep disturbances, depression, and anxiety were significantly superior in the patients administered PGB, with clinically relevant improvement (large effect size) while the changes in the non-PGB group were only moderate (Tables 4 and 5). The effect upon sleep showed a similar pattern for the six dimensions of the MOS-sleep scale, though none of the treatment groups showed relevant changes in the dimensions "snoring" or "waking up with shortness of breath or headache" (Table 5). On the other hand, with the exception of "sleep disturbance", which exhibited a moderate effect 
Table 3 Mean and magnitude of change (effect size) of the different pain parameters measured by the SF-MPQ according to treatment group

\begin{tabular}{|c|c|c|c|c|}
\hline Health outcome & Non-PGB $(N=155)^{\mathrm{a}}$ & $\begin{array}{l}\text { PGB monotherapy } \\
(N=473)^{\mathrm{a}}\end{array}$ & $\begin{array}{l}\text { PGB add-on } \\
(N=676)^{\mathrm{a}}\end{array}$ & $P$ \\
\hline \multicolumn{5}{|l|}{ SF-MPQ } \\
\hline Sensory & $-5.1(5.6)[0.88]$ & $-8.3(6.3)[1.38]$ & $-8.0(5.9)[1.33]$ & $<0.001$ \\
\hline Affective & $-2.2(2.7)[0.66]$ & $-2.9(3.0)[0.91]$ & $-3.0(2.9)[0.94]$ & $<0.001$ \\
\hline Total & $-7.4(7.6)[0.88]$ & $-11.2(8.5)[1.33]$ & $-11.0(8.0)[1.29]$ & $<0.001$ \\
\hline PPI & $-0.9(1.0)[1.13]$ & $-1.5(1.0)[1.88]$ & $-1.4(1.0)[1.75]$ & $<0.001$ \\
\hline \multicolumn{5}{|l|}{ SF-MPQ intensity (VAS) } \\
\hline $\mathrm{mm}$ & $-25.0(22.0)[1.63]$ & $-40.1(23.2)[2.75]$ & $-37.1(24.0)[2.42]$ & $<0.001$ \\
\hline$\%$ & $35.6(27.8)$ & $56.4(27.6)$ & $50.7(27.4)$ & $<0.001$ \\
\hline Responders $(\%)^{\mathrm{b}}$ & 32.9 & 62.8 & 56.3 & $<0.001$ \\
\hline $\begin{array}{l}\text { Cumulative days without pain } \\
\text { or mild pain (VAS }<40 \mathrm{~mm} \text { ) }\end{array}$ & $20.2(26.9)$ & $36.3(29.7)$ & $30.7(28.9)$ & $<0.001$ \\
\hline
\end{tabular}

Values given as mean (standard deviation) [effect size]

$V A S$ Visual analog scale, $P G B$ pregabalin, $P P I$ present pain intensity, $S F-M P Q$ Short Form McGill Pain Questionnaire

${ }^{\text {a }}$ Total number of patients analyzed; some subjects failed to report the data relating to certain variables

${ }^{b}$ Responders: patients with a reduction of at least $50 \%$ in pain intensity as scored by the VAS of the SF-MPQ

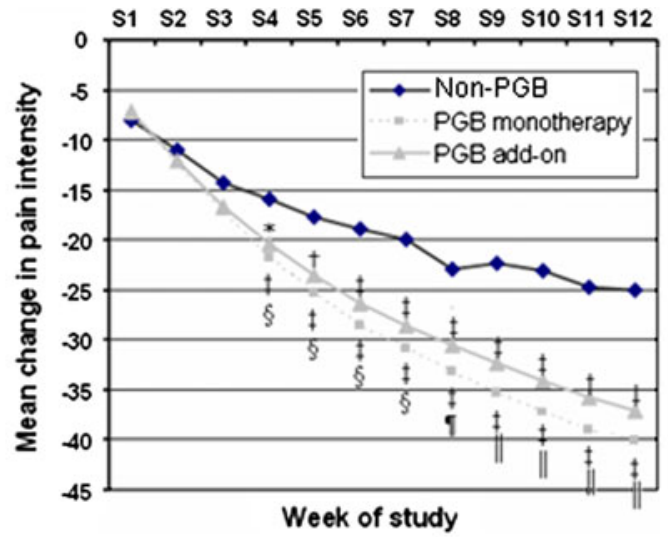

VAS: visual analog scale; PGB:pregabalin; S1-S12: week 1 to 12 ; SF-MPQ: Short Form McGill Pain Questionnaire.

${ }^{*} p<0.05,{ }^{\dagger}<00.01, I_{p}<0.001$ vs Non-PGB group; ${ }^{i p} p<0.05$ ip $<<0.01, \| p<0.001$ vs $P G B$ add-on

Fig. 2 Mean weekly change in pain intensity as scored by the VAS of the SF-MPQ

size, the changes in the non-PGB group for all the MOSSleep dimensions were small. In contrast, the PGB-treated groups showed large changes for "sleep disturbance" and "adequacy of sleep", with moderate changes for "amount of sleep" and "daytime somnolence" (Table 5).

All treatment groups showed relevant improvement in the impact of painful radiculopathy on patient perceived stress and social and working activities as measured by the SDI (Table 4). Once again, these changes were significantly greater in the two groups that received PGB. General patient health according to the EQ-5D VAS also improved significantly more in the PGB-treated groups, and the clinical impact was likewise greater as measured by the effect size (Table 4), in turn giving rise to a greater gain in QALYs in the groups exposed to PGB (Table 4). These

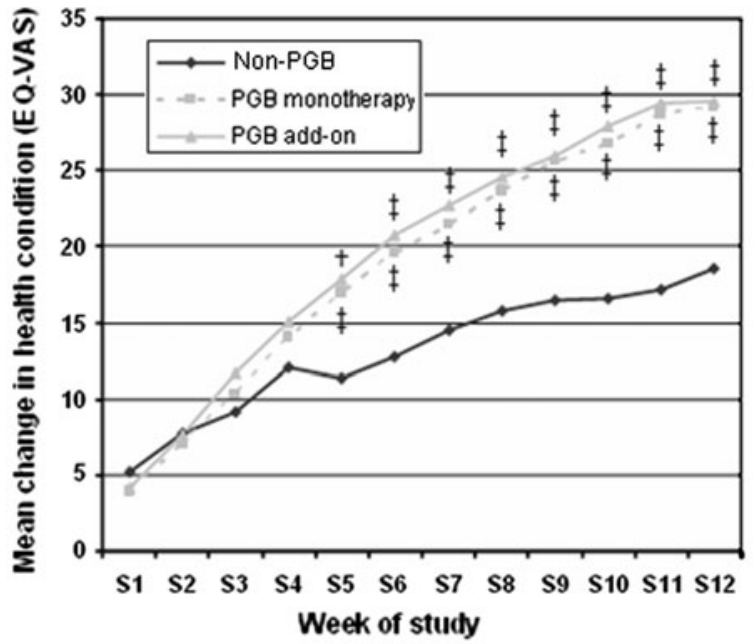

VAS: visual analog scale; PGB:pregabalin;

S1-S12: week 1 to 12; EQ: EQ-5D, ${ }^{\dagger} p<0.01, I_{p}<0.001$ vs Non-PGB group.

Fig. 3 Mean weekly change in health status as scored by the VAS of the EQ-5D

differences were seen to be significant from week 5 of the study, and maintained until week 12 (Fig. 3). In general terms, the benefit observed in each of the five dimensions of the EQ-5D was significantly greater in the groups treated with PGB, particularly among those patients that received the drug as monotherapy (Table 4).

\section{Discussion}

Few randomized clinical trials have been run in patients presenting with pain with a neuropathic component secondary to radiculopathy, and particularly in general in chronic 
Table 4 Mean and magnitude of change (effect size) of the patient reported health outcomes at the end of the study, according to treatment group

\begin{tabular}{|c|c|c|c|c|}
\hline Health outcome & $\begin{array}{l}\text { Non-PGB } \\
(N=155)^{\mathrm{a}}\end{array}$ & $\begin{array}{l}\text { PGB monotherapy } \\
(N=473)^{\mathrm{a}}\end{array}$ & $\begin{array}{l}\text { PGB add-on } \\
(N=676)^{\mathrm{a}}\end{array}$ & $P$ \\
\hline \multicolumn{5}{|l|}{ HADS } \\
\hline Depression $(0-21)$ & $-2.5(4.0)[0.55]$ & $-3.9(4.3)[0.87]$ & $-3.8(4.2)[0.86]$ & $<0.001$ \\
\hline Anxiety $(0-21)$ & $-2.2(3.4)[0.56]$ & $-3.8(4.0)[0.97]$ & $-3.6(3.6)[0.95]$ & $<0.001$ \\
\hline \multicolumn{5}{|l|}{ SDI } \\
\hline Disability $(0-30)^{\mathrm{b}}$ & $-5.7(5.9)[0.95]$ & $-9.2(6.5)[1.59]$ & $-8.9(6.3)[1.65]$ & $<0.001$ \\
\hline Perceived stress $(0-100)$ & $-1.8(2.1)[0.86]$ & $-3.0(2.3)[1.43]$ & $-2.8(2.2)[1.47]$ & $<0.001$ \\
\hline Perceived social support, \% (0-100) & $-1.4(1.8)[0.06]$ & $-2.4(2.4)[0.11]$ & $-1.2(1.9)[0.05]$ & 0.004 \\
\hline \multicolumn{5}{|l|}{ EQ-5D } \\
\hline VAS $(0-100)$ & $18.6(22.3)[1.08]$ & $29.2(22.2)[1.60]$ & $29.5(21.2)[1.69]$ & $<0.001$ \\
\hline Mobility $^{\mathrm{c}}, n(\%)$ & $77(50.7)$ & $303(65.3)$ & $410(61.1)$ & $<0.001$ \\
\hline Personal care ${ }^{\mathrm{c}}, n(\%)$ & $90(59.2)$ & $360(77.6)$ & $487(72.9)$ & $<0.001$ \\
\hline Daily life activities $^{\mathrm{c}}, n(\%)$ & $50(32.9)$ & $252(54.7)$ & $306(45.7)$ & $<0.001$ \\
\hline Without pain, $n(\%)$ & $26(17.1)$ & $165(35.7)$ & $160(23.9)$ & $<0.001$ \\
\hline Without anxiety/depression, $n(\%)$ & $74(49.0)$ & $302(65.1)$ & $388(58.3)$ & 0.002 \\
\hline QALYs gained & $0.0284(0.0409)$ & $0.0407(0.0389)$ & $0.0427(0.0369)$ & $<0.001$ \\
\hline
\end{tabular}

Values given as mean (standard deviation) [effect size]

VAS Visual analog scale, HADS Hospital Anxiety Depression Scale, MOS Medical Outcomes Study, PGB pregabalin, SDI Sheehan Disability Inventory, $Q A L Y$ Quality-adjusted life year

a Total number of patients analyzed; some subjects failed to report the data relating to certain variables

b Sum of the scores of the first three items

${ }^{c}$ Patients responding without problems in the item

Table 5 Mean and magnitude of change (effect size) of the different dimensions of sleep measured by the MOS-sleep, according to treatment group

\begin{tabular}{|c|c|c|c|c|}
\hline Dimension of the MOS-sleep & $\begin{array}{l}\text { Non-PGB } \\
(N=155)^{\mathrm{a}}\end{array}$ & $\begin{array}{l}\text { PGB monotherapy } \\
(N=473)^{\mathrm{a}}\end{array}$ & $\begin{array}{l}\text { PGB add-on } \\
(N=676)^{\mathrm{a}}\end{array}$ & $P$ \\
\hline Summary index $(0-100)$ & $-9.3(16.0)[0.55]$ & $-17.3(18.1)[1.01]$ & $-17.3(18.1)[1.01]$ & $<0.001$ \\
\hline Sleep disturbance $(0-100)$ & $-11.2(18.5)[0.56]$ & $-19.3(20.1)[0.99]$ & $-20.0(19.8)[1.02]$ & $<0.001$ \\
\hline Snoring $(0-100)$ & $0.9(23.2)[0.03]$ & $-5.5(23.6)[0.19]$ & $-5.1(20.8)[0.18]$ & 0.001 \\
\hline Shortness of breath $(0-100)$ & $-2.1(27.0)[0.08]$ & $-10.7(23.8)[0.40]$ & $-12.3(24.7)[0.47]$ & $<0.001$ \\
\hline Sleep quantity, hours & $+0.4(1.2)[0.27]$ & $+0.9(1.3)[0.64]$ & $+1.0(1.2)[0.77]$ & $<0.001$ \\
\hline Adequacy of sleep (100-0) & $+11.3(21.5)[0.48]$ & $+21.2(25.3)[0.92]$ & +20.7 (24.3) [0.89] & $<0.001$ \\
\hline Daytime somnolence $(0-100)$ & $-5.6(18.9)[0.29]$ & $-10.9(19.6)[0.57]$ & $-9.5(19.6)[0.50]$ & $<0.001$ \\
\hline
\end{tabular}

Values given as mean (standard deviation) [effect size]

MOS Medical Outcomes Study, $P G B$ pregabalin

${ }^{\text {a }}$ Total number of patients analyzed; some subjects failed to report the data relating to certain variables

pain of mixed origin [16]. In addition, very few current trials address the pharmacological management of these clinical conditions. Our data appear to be the first involving PGB for the management of cervical and lumbosacral radiculopathy under conditions of routine clinical practice in the primary care setting. Our findings suggest that PGB is effective under "Real World" conditions for treating pain of this kind and also for ensuring clinically relevant improvement in the associated symptoms of anxiety, depression, and sleep disturbances-with amelioration of patient disability and improvement in quality of life.
Monotherapy with PGB, or as an add-on therapy, produced a very marked decrease in pain (over $50 \%$ ), with a large effect size. The proportion of responders, $63 \%$ and $56 \%$ in the monotherapy and add-on groups, respectively, was at least similar to that recorded in clinical trials of PGB among patients with diabetic neuropathy (39 and 48\%) [23-25], postherpetic neuralgia (28-50\%) [27-29], and superior to the proportion observed in patients with central neuropathic pain associated with spinal cord injury (22\%) [30]. The apparent analgesic superiority versus the subjects that did not receive PGB proved consistent across all 
outcome measures, with large effect sizes for the most part, and likewise superior to those seen in the non-PGB patients. These data point to the broad activity spectrum of PGB in application to pain with a neuropathic component. Although always difficult to interpret in the context of an observational study, it cannot be ruled out that this apparent superiority may be due in part to inadequate management of patients belonging to the non-PGB group. In a large percentage of cases, these latter patients were treated with NSAIDs (67\%) or paracetamol (37\%). While these drugs have an effect upon the somatic component of pain, they have not been shown to be effective in the management of neuropathic pain. In contrast, only $13 \%$ of the patients received gabapentin, amitriptyline in 5\%, and $25 \%$ received opioids. This situation is almost analogous to that described in other countries such as the United Kingdom or Spain, likewise in the primary care setting, where NSAIDs are widely used for the treatment of mixed presentations $(65 \%)$, while the use of drugs of proven clinical efficacy in the treatment of neuropathic pain, such as antiepileptic agents or tricyclic antidepressants, is more limited (10 and $3 \%$, respectively) $[43,44]$.

The effect of PGB on comorbid symptoms of sleep disturbances, depression, and anxiety, was significantly superior in the patients administered PGB, with large effect sizes, versus the moderate changes seen in the non-PGB group. Given the frequent co-occurrence of these comorbidities in such patients [21], the role of PGB proves particularly useful in such situations. While opiods have been shown to be effective in reducing neuropathic pain [16], their beneficial effects upon patient mood, disability, and quality of life are not consistent [45, 46]. In addition, the beneficial effect of PGB on treating comorbid conditions could reduce health care resource utilization and costs. As an example, it has been reported that in patients with back pain, existing physical and mental comorbidities, led to a significant increase in health care costs [47]. Globally, the superior effectiveness of PGB in ameliorating pain, and its greater effect upon associated comorbidities, could explain the improvement we recorded in relation to social and working incapacitation and quality of life, compared with the patients administered other treatments.

The mean PGB dose used in our study, about $190 \mathrm{mg} /$ day, lies within the effective dosing range for neuropathic pain $(150-600 \mathrm{mg} /$ day), and perhaps is at the lower limit when compared with the doses used in clinical trials with PGB. Most of the PGB trials mentioned above made use of a fixed-dose scheme; comparisons with our study are therefore difficult to establish. However, in a randomized clinical study of PGB versus placebo in patients with neuropathic pain associated to peripheral diabetic neuropathy or postherpetic neuropathy, in which a flexible dosing scheme was used, the mean dose was almost double what we observed in routine practice ( $372 \mathrm{mg} /$ day) [26]. Whether lower doses are needed in clinical practice, or whether simple underdosing is involved, is a question which our study was unable to answer. However, underdosing seems more likely, since the prescription of doses lower than those recommended for pain, including pain of neuropathic origin, is often reported in the literature [20,43].

Despite the lack of evidence from randomized clinical trials, it is common in clinical practice to use combinations of several drugs to treat pain with a neuropathic component [48-51]. In our analysis, the PGB add-on treatment group yielded superior results compared with patients administered other treatments, and with the exception of pain, these results were moreover analogous to those obtained with PGB in monotherapy. While statistically significant, the differences observed in pain management with PGB as monotherapy compared with the PGB add-on group are of scant clinical relevance for a number of reasons: the patients in the PGB add-on group generally presented with more severe symptoms; the differences in effect size between the two PGB-treated groups were not large; and the impact upon patient disability and quality of life was similar in both groups.

Our study provides data on the effectiveness of adding PGB to existing analgesic treatment. Nevertheless, it would be worthwhile to conduct controlled clinical trials to evaluate the possibility that PGB combined with an analgesic could be superior to the drugs in monotherapy for the management of painful radiculopathy of mixed origin. There is some evidence to suggest that this may be the case. Some analgesics such as paracetamol or the NSAIDs are ineffective in application to pure neuropathic pain condition, but may be of help in the presence of a nociceptive component. On the other hand, a randomized and placebo controlled trial involving the combination of pregabalin and an NSAID has shown better performance than the drugs in monotherapy, as preoperative analgesia in vertebral fusion surgery [52].

Our study, however, has some limitations that must be taken into account. Because of its observational nature, it is exposed to bias and confounding factors. The impact of such bias, particularly selection bias, is difficult to establish. However, at least in the PGB add-on treatment group, such bias probably acts against the drug, since these were more seriously affected patients. On the other hand, the logical open-label design may have overestimated the effect of treatment. Another limitation of our study is represented by the fact that the study did not specifically assess the effect of pharmacological intervention, hence we have no systematic evaluation of the tolerability of the treatments. However, the high proportion of patients that completed the treatment in all the groups analyzed, and the low incidence of drop-outs attributable to adverse effects, suggest that the 
three treatment strategies were very well tolerated. Last, it is worthy to comment on the diagnosis of radiculopathy in the study. While patients were identified using ICD-10 classification criteria for radiculopathies in conjunction with a diagnostic tool administered to assist general practitioners in categorizing the neuropathic component of pain, we cannot exclude the possibility of misdiagnosis to some extent.

\section{Conclusions}

Overall, in spite of these limitations, the results of this analysis complement the findings observed with PGB in clinical trials, then consolidating PGB as an effective therapy for the treatment of the neuropathic component of pain in subjects with cervical or lumbosacral radiculopathy in real world conditions of care. This effectiveness resulted in a reduction of the associated symptoms of pain in routine medical practice, leading to lower disability and better quality of life of patients. To conclude, our analysis suggests that in routine clinical practice, pregabalin both as monotherapy and in combination, is associated with considerable pain reduction, and important improvement in associated symptoms such as sleep, affective disorders, and anxiety. In addition, PGB treatment reduces associated disability and improves the health condition of patients with neuropathic pain associated with cervical or lumbosacral radiculopathy. The possible superiority of this drug over other treatments, the usefulness of pregabalin doses higher than those used in this analysis, and the potential utility of combining the drug with other treatments for the management of this type of neuropathic pain are aspects that should be further examined in the context of randomized clinical trials.

Acknowledgments The authors thank Fernando Rico-Villademoros $\mathrm{MD}$, for his assistance in the preparation of the draft of this manuscript. This study was funded by an unrestricted grant from Pfizer Spain.

Competing interests One of the authors of this study, Javier Rejas, is an employee of Pfizer Spain, which is the entity funding this project. $\mathrm{M}^{\mathrm{a}}$ Teresa Saldaña, Ana Navarro, and Concepción Pérez have received honoraries from Pfizer Spain.

Open Access This article is distributed under the terms of the Creative Commons Attribution Noncommercial License which permits any noncommercial use, distribution, and reproduction in any medium, provided the original author(s) and source are credited.

\section{References}

1. Verhaak PF, Kerssens JJ, Dekker J, Sorbi MJ, Bensing JM (1998) Prevalence of chronic benign pain disorder among adults: a review of the literature. Pain 77(3):231-239. doi:10.1016/S0304-3959(98) 00117-1

2. Lawrence RC, Helmick CG, Arnett FC, Deyo RA, Felson DT, Giannini EH, Heyse SP, Hirsch R, Hochberg MC, Hunder GG,
Liang MH, Pillemer SR, Steen VD, Wolfe F (1998) Estimates of the prevalence of arthritis and selected musculoskeletal disorders in the United States. Arthritis Rheum 41(5):778-799. doi:10.1002/ 1529-0131(199805)41:5<778::AID-ART4>3.0.CO;2-V

3. Bressler HB, Keyes WJ, Rochon PA, Badley E (1999) The prevalence of low back pain in the elderly. A systematic review of the literature. Spine 24(17):1813-1819. doi:10.1097/00007632199909010-00011

4. Elliott AM, Smith BH, Penny KI, Smith WC, Chambers WA (1999) The epidemiology of chronic pain in the community. Lancet 354(9186): 1248-1252. doi:10.1016/S0140-6736(99)03057-3

5. van der Donk J, Schouten JSAG, Passchier J, van Romunde LKJ, Valkenberg HA (1991) The association of neck pain with radiological abnormalities of the cervical spine and personality traits in a general population. J Rheumatol 18:1884-1889

6. Cote P, Cassidy JD, Carroll L (1998) The Saskatchewan Health and Back Pain Survey. The prevalence of neck pain and related disability in Saskatchewan adults. Spine 23(15):1689-1698. doi:10.1097/00007632-199808010-00015

7. Webb R, Brammah T, Lunt M, Urwin M, Allison T, Symmons D (2003) Prevalence and predictors of intense, chronic, and disabling neck and back pain in the UK general population. Spine 28(11):1195-1202. doi:10.1097/00007632-200306010-00021

8. Carey TS, Evans AT, Hadler NM, Lieberman G, Kalsbeek WD, Jackman AM, Fryer JG, McNutt RA (1996) Acute severe low back pain. A population-based study of prevalence and care-seeking. Spine 21(3):339-344. doi:10.1097/00007632-199602010-00018

9. Loney PL, Stratford PW (1999) The prevalence of low back pain in adults: a methodological review of the literature. Phys Ther 79(4):384-396

10. Berger A, Dukes EM, Oster G (2004) Clinical characteristics and economic costs of patients with painful neuropathic disorders. J Pain 5(3):143-149. doi:10.1016/j.jpain.2003.12.004

11. McDermott AM, Toelle TR, Rowbotham DJ, Schaefer CP, Dukes EM (2006) The burden of neuropathic pain: results from a crosssectional survey. Eur J Pain 10(2):127-135. doi:10.1016/j.ejpain. 2005.01.014

12. Lachaine J, Gordon A, Choiniere M, Collet JP, Dion D, Tarride JE (2007) Painful neuropathic disorders: an analysis of the Regie de l'Assurance Maladie du Quebec database. Pain Res Manag 12(1):31-37

13. Smith MT, Haythornthwaite JA (2004) How do sleep disturbance and chronic pain inter-relate? Insights from the longitudinal and cognitive-behavioral clinical trials literature. Sleep Med Rev 8(2):119-132. doi:10.1016/S1087-0792(03)00044-3

14. Rush AJ, Polatin P, Gatchel RJ (2000) Depression and chronic low back pain: establishing priorities in treatment. Spine 25(20):25662571. doi:10.1097/00007632-200010150-00004

15. McWilliams LA, Goodwin RD, Cox BJ (2004) Depression and anxiety associated with three pain conditions: results from a nationally representative sample. Pain 111(1-2):77-83. doi:10.1016/ j.pain.2004.06.002

16. Finnerup NB, Otto M, McQuay HJ, Jensen TS, Sindrup SH (2005) Algorithm for neuropathic pain treatment: an evidence based proposal. Pain 118(3):289-305. doi:10.1016/j.pain.2005.08.013

17. Harden N, Cohen M (2003) Unmet needs in the management of neuropathic pain. J Pain Symptom Manage 25(5 Suppl):S12-S17. doi:10.1016/S0885-3924(03)00065-4

18. Tolle T, Xu X, Sadosky AB (2006) Painful diabetic neuropathy: a cross-sectional survey of health state impairment and treatment patterns. J Diabetes Complications 20(1):26-33. doi:10.1016/ j.jdiacomp.2005.09.007

19. Tolle T, Dukes E, Sadosky A (2006) Patient burden of trigeminal neuralgia: results from a cross-sectional survey of health state impairment and treatment patterns in six European countries. Pain Pract 6(3):153-160. doi:10.1111/j.1533-2500.2006.00079.x 
20. van Seventer R, Sadosky A, Lucero M, Dukes E (2006) A crosssectional survey of health state impairment and treatment patterns in patients with postherpetic neuralgia. Age Ageing 35(2):132137. doi:10.1093/ageing/afj048

21. Argoff CE (2007) The coexistence of neuropathic pain, sleep, and psychiatric disorders: a novel treatment approach. Clin J Pain 23(1):15-22. doi:10.1097/01.ajp.0000210945.27052.b3

22. Tassone DM, Boyce E, Guyer J, Nuzum D (2007) Pregabalin: a novel gamma-aminobutyric acid analogue in the treatment of neuropathic pain, partial-onset seizures, and anxiety disorders. Clin Ther 29(1):26-48. doi:10.1016/j.clinthera.2007.01.013

23. Rosenstock J, Tuchman M, LaMoreaux L, Sharma U (2004) Pregabalin for the treatment of painful diabetic peripheral neuropathy: a double-blind, placebo-controlled trial. Pain 110(3):628-638. doi:10.1016/j.pain.2004.05.001

24. Lesser H, Sharma U, LaMoreaux L, Poole RM (2004) Pregabalin relieves symptoms of painful diabetic neuropathy: a randomized controlled trial. Neurology 63(11):2104-2110

25. Richter RW, Portenoy R, Sharma U, Lamoreaux L, Bockbrader H, Knapp LE (2005) Relief of painful diabetic peripheral neuropathy with pregabalin: a randomized, placebo-controlled trial. J Pain 6(4):253-260. doi:10.1016/j.jpain.2004.12.007

26. Freynhagen R, Strojek K, Griesing T, Whalen E, Balkenohl M (2005) Efficacy of pregabalin in neuropathic pain evaluated in a 12-week, randomised, double-blind, multicentre, placebocontrolled trial of flexible- and fixed-dose regimens. Pain 115(3):254-263

27. Dworkin RH, Corbin AE, Young JP Jr, Sharma U, LaMoreaux L, Bockbrader H, Garofalo EA, Poole RM (2003) Pregabalin for the treatment of postherpetic neuralgia: a randomized, placebo-controlled trial. Neurology 60(8):1274-1283

28. Sabatowski R, Galvez R, Cherry DA, Jacquot F, Vincent E, Maisonobe P, Versavel M, 1008-045 Study Group (2004) Pregabalin reduces pain and improves sleep and mood disturbances in patients with post-herpetic neuralgia: results of a randomised, placebo-controlled clinical trial. Pain 109(1-2):26-35. doi:10.1016/ j.pain.2004.01.001

29. van Seventer R, Feister HA, Young JP Jr, Stoker M, Versavel M, Rigaudy L (2006) Efficacy and tolerability of twice-daily pregabalin for treating pain and related sleep interference in postherpetic neuralgia: a 13-week, randomized trial. Curr Med Res Opin 22(2):375-384. doi:10.1185/030079906X80404

30. Siddall PJ, Cousins MJ, Otte A, Griesing T, Chambers R, Murphy TK (2006) Pregabalin in central neuropathic pain associated with spinal cord injury: a placebo-controlled trial. Neurology 67(10):1792-1800. doi:10.1212/01.wnl.0000244422.45278.ff

31. Saldaña MT, Navarro A, Pérez C, Masramon X, Rejas J (2007) Health, non-health resources utilization and costs of treating refractory painful Radiculopathy in Primary Care Settings (PCS) under routine medical practice in Spain. Value Health 10:A464. Abstract

32. Bouhassira D, Attal N, Fermanian J, Alchaar H, Gautron M, Masquelier E, Rostaing S, Lanteri-Minet M, Collin E, Grisart J, Boureau F (2004) Development and validation of the Neuropathic Pain Symptom Inventory. Pain 108(3):248-257. doi:10.1016/ j.pain.2003.12.024

33. Bouhassira D, Attal N, Alchaar H, Boureau F, Brochet B, Bruxelle J, Cunin G, Fermanian J, Ginies P, Grun-Overdyking A, JafariSchluep H, Lanteri-Minet M, Laurent B, Mick G, Serrie A, Valade $\mathrm{D}$, Vicaut $\mathrm{E}$ (2005) Comparison of pain syndromes associated with nervous or somatic lesions and development of a new neuropathic pain diagnostic questionnaire (DN4). Pain 114(1-2):29-36. doi:10.1016/j.pain.2004.12.010

34. Perez C, Galvez R, Huelbes S, Insausti J, Bouhassira D, Diaz S, Rejas J (2007) Validity and reliability of the Spanish version of the DN4 (Douleur Neuropathique 4 questions) questionnaire for differential diagnosis of pain syndromes associated to a neuro- pathic or somatic component. Health Qual Life Outcomes 5:66. doi:10.1186/1477-7525-5-66

35. Melzack R (1987) The short-form McGill Pain Questionnaire. Pain 30(2):191-197. doi:10.1016/0304-3959(87)91074-8

36. Sheehan DV, Harnett-Sheehan K, Raj BA (1996) The measurement of disability. Int Clin Psychopharmacol 11(Suppl 3):89-95. doi:10.1097/00004850-199606003-00015

37. Hays RD, Stewart AL (1992) Sleep measures. In: Stewart AL, Ware JE (eds) Measuring functioning and well-being: The Medical Outcomes Study approach. Duke University Press, Durham, NC, pp 235-259

38. Rejas J, Ribera MV, Ruiz M, Masrramon X (2007) Psychometric properties of the MOS (Medical Outcomes Study) Sleep Scale in patients with neuropathic pain. Eur J Pain 11(3):329-340. doi:10.1016/j.ejpain.2006.05.002

39. Zigmond AS, Snaith RP (1983) The hospital anxiety and depression scale. Acta Psychiatr Scand 67(6):361-370. doi:10.1111/ j.1600-0447.1983.tb09716.x

40. TheEuroQol Group (1990) EuroQol-a new facility for the measurement of health-related quality of life. Health Policy 16(3):199-208. doi:10.1016/0168-8510(90)90421-9

41. Kazis LE, Anderson JJ, Meenan RF (1989) Effect sizes for interpreting changes in health status. Med Care 27:S178-S189. doi:10.1097/00005650-198903001-00015

42. Brooks R (1996) EuroQoL: the current state of play. Health Policy 37:53-72. doi:10.1016/0168-8510(96)00822-6

43. Gore M, Dukes E, Rowbotham DJ, Tai KS, Leslie D (2007) Clinical characteristics and pain management among patients with painful peripheral neuropathic disorders in general practice settings. Eur J Pain 11(6):652-664. doi:10.1016/j.ejpain.2006.10.004

44. Rodríguez MJ, García AJ (2007) A Registry of the Aetiology and Costs of Neuropathic Pain in Pain Clinics: Results of the Registry of Etiologies and Costs (REC) in Neuropathic Pain Disorders Study. Clin Drug Investig 27(11):771-782

45. Watson CP, Moulin D, Watt-Watson J, Gordon A, Eisenhoffer J (2003) Controlled-release oxycodone relieves neuropathic pain: a randomized controlled trial in painful diabetic neuropathy. Pain 105(1-2):71-78. doi:10.1016/S0304-3959(03)00160-X

46. Gimbel JS, Richards P, Portenoy RK (2003) Controlled-release oxycodone for pain in diabetic neuropathy: a randomized controlled trial. Neurology 60(6):927-934

47. Ritzwoller DP, Crounse L, Shetterly S, Rublee D (2006) The association of comorbidities, utilization and costs for patients identified with low back pain. BMC Musculoskelet Disord 7:72. doi:10.1186/1471-2474-7-72

48. Sindrup SH, Jensen TS (2002) Pharmacotherapy of trigeminal neuralgia. Clin J Pain 18(1):22-27. doi:10.1097/00002508200201000-00004

49. Dworkin RH, Backonja M, Rowbotham MC, Allen RR, Argoff CR, Bennett GJ, Bushnell MC, Farrar JT, Galer BS, Haythornthwaite JA, Hewitt DJ, Loeser JD, Max MB, Saltarelli M, Schmader KE, Stein C, Thompson D, Turk DC, Wallace MS, Watkins LR, Weinstein SM (2003) Advances in neuropathic pain: diagnosis, mechanisms, and treatment recommendations. Arch Neurol 60(11):1524-1534. doi:10.1001/archneur.60.11.1524

50. Gilron I, Bailey JM (2003) Trends in opioid use for chronic neuropathic pain: a survey of patients pursuing enrollment in clinical trials. Can J Anaesth 50(1):42-47

51. Gore M, Brandenburg NA, Hoffman DL, Tai KS, Stacey B (2006) Burden of illness in painful diabetic peripheral neuropathy: the patients' perspectives. J Pain 7(12):892-900. doi:10.1016/ j.jpain.2006.04.013

52. Reuben SS, Buvanendran A, Kroin JS, Raghunathan K (2006) The analgesic efficacy of celecoxib, pregabalin, and their combination for spinal fusion surgery. Anesth Analg 103(5):1271-1277. doi:10.1213/01.ane.0000237279.08847.2d 